University of Nebraska - Lincoln

DigitalCommons@University of Nebraska - Lincoln

Faculty Publications from the Harold W. Manter Laboratory of Parasitology

2011

ERECTION OF IBIRHYNCHUS GEN. NOV. (ACANTHOCEPHALA:

POLYMORPHIDAE), BASED ON MOLECULAR AND

MORPHOLOGICAL DATA

\author{
Martin Garcia-Varela \\ Instituto de Investigaciones Biomedicas Mexico, garciav@servidor.unam.mx \\ Gerardo Pérez-Ponce de León \\ Universidad Nacional Autónoma de México \\ Francisco J. Aznar \\ Universitat de Valencia \\ Steven A. Nadler \\ University of California - Davis, sanadler@ucdavis.edu
}

Follow this and additional works at: https://digitalcommons.unl.edu/parasitologyfacpubs

Part of the Parasitology Commons

Garcia-Varela, Martin; Pérez-Ponce de León, Gerardo; Aznar, Francisco J.; and Nadler, Steven A., "ERECTION OF IBIRHYNCHUS GEN. NOV. (ACANTHOCEPHALA: POLYMORPHIDAE), BASED ON MOLECULAR AND MORPHOLOGICAL DATA" (2011). Faculty Publications from the Harold W. Manter Laboratory of Parasitology. 719.

https://digitalcommons.unl.edu/parasitologyfacpubs/719

This Article is brought to you for free and open access by the Parasitology, Harold W. Manter Laboratory of at DigitalCommons@University of Nebraska - Lincoln. It has been accepted for inclusion in Faculty Publications from the Harold W. Manter Laboratory of Parasitology by an authorized administrator of DigitalCommons@University of Nebraska - Lincoln. 


\title{
ERECTION OF IBIRHYNCHUS GEN. NOV. (ACANTHOCEPHALA: POLYMORPHIDAE), BASED ON MOLECULAR AND MORPHOLOGICAL DATA
}

\author{
Martín García-Varela, Gerardo Pérez-Ponce de León, Francisco J. Aznar ${ }^{\star}$, and Steven A. Nadler† \\ Departamento de Zoología, Instituto de Biología, Universidad Nacional Autónoma de México, Avenida Universidad 3000; Ciudad Universitaria, \\ C.P. 04510, Distrito Federal, México.e-mail: garciav@servidor.unam.mx
}

\begin{abstract}
The genus Southwellina is composed of 3 described species, i.e., S. hispida (the type species), S. dimorpha, and $S$. macracanthus. All 3 are endoparasites of fish-eating birds that have worldwide distributions. Morphologically, the genus is characterized by possessing a short and compact trunk, 2 fields of spines in the anterior region of the trunk (in at least 1 sex), a short cylindrical proboscis (sometimes with a swollen region armed with numerous longitudinal rows of hooks), a double-walled proboscis receptacle, and 4 tubular cement glands in males. In the current study, specimens identified as $S$. dimorpha were collected from Eudocimus albus (white ibis), the type host from the Gulf of Mexico. Sequences of 2 nuclear genes (small subunit [SSU] and long subunit [LSU] ribosomal DNA) and 1 mitochondrial gene (cytochrome $c$ oxidase subunit 1 [cox 1]) of $S$. dimorpha and $S$. hispida were obtained and used to reconstruct the phylogenetic relationships of both species with respect to published sequences of 11 species representing 6 genera of Polymorphidae. Maximum parsimony (MP) and maximum likelihood (ML) analyses of the concatenated data set (SSU + LSU + cox 1) were identical in depicting Southwellina as paraphyletic, indicating that the genus should be revised. The MP and ML trees identified S. hispida as a sister to Polymorphus brevis, whereas $S$. dimorpha was a sister to Hexaglandula corynosoma. Morphologically, $S$. dimorpha is distinct from $H$. corynosoma, which is characterized by a short trunk with 1 field of spines in the anterior part of the trunk in both genders, and males with 6 tubular cement glands. The genetic divergence estimated from a concatenated data set between 2 isolates of $S$. hispida and $S$. dimorpha ranged from 10.7 to $11.0 \%$. This range of genetic divergence is similar to that found among other genera of Polymorphidae, which extends from 6.0 to $12.0 \%$. Southwellina dimorpha differs from $S$. hispida in the shape of the proboscis and the presence of 1 field of spines ( $S$. dimorpha) versus 2 fields (S. hispida) on the anterior region of the trunk in females. Based on the phylogenetic position of $S$. dimorpha within Polymorphidae, coupled with levels of genetic divergence and, more importantly, the morphological and ecological (host specificity) differences, we propose the erection of a new genus to accommodate $S$. dimorpha.
\end{abstract}

Members of Polymorphidae Meyer, 1931 are intestinal parasites of marine mammals, fish-eating birds, and waterfowl, with a worldwide distribution. Their life cycles typically include a crustacean (amphipod, copepod, or decapod) as an intermediate host and may include fish, snakes, frogs, or toads as paratenic hosts (Schmidt, 1985; Hoberg, 1986; Nickol et al., 1999, 2002). Polymorphids include approximately 127 species, classified into 11 genera (Schmidt, 1973; Dimitrova and Goergiev, 1994; Nickol et al., 1999, 2002; Aznar et al., 2006). Currently, Southwellina Witenberg, 1932 is a genus composed of 3 described species (Schmidt, 1973; Amin, 1985). The type species, S. hispida Van Cleave 1925, is a parasite of fish-eating birds, with a worldwide distribution (Schmidt, 1973; Courtney and Forrester, 1974; Richardson and Cole, 1997; Dezfuli et al., 2002; Norman et al., 2003; Font, 2007; García-Varela et al., 2009). Southwellina macracanthus Ward and Winter, 1952 was described from cystacanths of marine fishes obtained from the Pacific Coast of the United States. Southwellina dimorpha Schmidt, 1973 was described from the intestine of Eudocimus albus (white ibis) from Florida, and recently it was found in the intestine of Grus americana (whooping crane) (Richardson and Font, 2006). Species of Southwellina are characterized by possessing a short and compact trunk, 2 fields of spines in the anterior region of the trunk (in at least 1 sex), a short cylindrical proboscis armed with numerous longitudinal rows of hooks, a double-walled and cylindrically shaped proboscis receptacle, and lemisci that are longer than the proboscis receptacle. Males possess 2 testes in the

Received 25 September 2009; revised 8 April 2010, 20 September 2010; accepted 23 September 2010.

* Departamento de Biología Animal, Instituto Cavanilles de Biodiversidad y Biología Evolutiva, Universitat de Valencia, Burjasot, Valencia, Spain.

$\dagger$ Department of Nematology, University of California, Davis, California 95616-8668

DOI: $10.1645 / G E-2350.1$ anterior part of the trunk and 4 tubular cement glands (Schmidt, 1973).

In the present study, specimens identified as $S$. dimorpha and $S$. hispida were used for molecular phylogenetic inference in an analysis including other members of Polymorphidae. Sequences of the small (SSU) and large (LSU) subunit nuclear ribosomal DNA and a region of the mitochondrial cytochrome $c$ oxidase subunit I ( $\operatorname{cox} 1)$ gene were obtained for both species of Southwellina. Sequences of both species were aligned with previously acquired data (see García-Varela et al., 2009) that included representatives of 6 genera of Polymorphidae (Polymorphus Lühe, 1911, i.e., Andracantha Schmidt, 1975, Pseudocorynosoma Aznar, PérezPonce de León and Raga, 2006, Corynosoma Lühe, 1904, Hexaglandula Petrochenko, 1950, Profilicollis Meyer, 1931), and 3 outgroup taxa, with the aim of examining the phylogenetic position and the sister-group relationships of $S$. hispida and $S$. dimorpha within Polymorphidae. In addition, a detailed morphological comparison was made between specimens of $S$. hispida and S. dimorpha to confirm the molecular findings.

\section{MATERIALS AND METHODS}

\section{Specimens and DNA isolation}

Adult acanthocephalans were collected from 5 white ibis (Eudocimus albus) from 2 localities in the Gulf of Mexico, i.e., Los Chivos, Veracruz $\left(18^{\circ} 56^{\prime} 13^{\prime \prime} \mathrm{N}, 95^{\circ} 58^{\prime} 08^{\prime \prime} \mathrm{W}\right)$ and Catemaco, Veracruz $\left(18^{\circ} 25^{\prime} \mathrm{N}, 95^{\circ} 07^{\prime} \mathrm{W}\right)$. Worms were washed 3 times in $0.9 \%(\mathrm{w} / \mathrm{v})$ saline, preserved in absolute ethanol, and stored at $4 \mathrm{C}$. For morphological identification, some specimens were stained with Meyer's paracarmine, cleared with methyl salicylate, and mounted on slides using Canada balsam. Parasites collected from Eudocimus albus were identified as $S$. dimorpha by conventional morphological criteria following keys of Yamaguti (1963) and Petrochenko (1958) and the original and revised descriptions of the species (Schmidt, 1973). Avian definitive hosts were identified using the field guides of Howell and Webb (1995) and the American Ornithologists' Union (1998). Voucher specimens were deposited at the Colección Nacional de Helmintos, Instituto de Biología, UNAM, México City, México (Table I). 
TABLE I. Specimen information and GenBank accession numbers for specimens studied in this work. Sequences marked with an asterisk $(*)$ were obtained in this study. ND, not determined. The numbers 1 and 2 correspond with the same numbers in Figures 1 and 2 .

\begin{tabular}{|c|c|c|c|c|c|c|}
\hline Species & Host & Locality & $\begin{array}{l}\text { Vouchers } \\
\text { (CNHE) }\end{array}$ & $\begin{array}{c}\text { GenBank } \\
\text { accession Cox }\end{array}$ & $\begin{array}{c}\text { GenBank } \\
\text { accession SSU }\end{array}$ & $\begin{array}{c}\text { GenBank } \\
\text { accession LSU }\end{array}$ \\
\hline Andracantha gravida & Phalacrocorax auritus & Yucatán, México & 5997 & EU267822 & EU267802 & EU267814 \\
\hline Corynosoma magdaleni & $\begin{array}{l}\text { Phoca hispida } \\
\text { saimensis }\end{array}$ & $\begin{array}{l}\text { Lake Saimaa, } \\
\text { Finland }\end{array}$ & & EF467872 & EU267803 & EU267815 \\
\hline Ibirhynchus dimorpha & Eudocimus albus & Veracruz, México & 6164 & GQ981438* & GQ981436* & GQ981437* \\
\hline Hexaglandula corynosoma & Nyctanassa violacea & Veracruz, México & 5765 & EF467869 & EU267808 & EU267817 \\
\hline Polymorphus brevis & Nycticorax nycticorax & Michoacán, México & 5778 & DQ089717 & AF064812 & AY829105 \\
\hline Polymorphus minutus & Gammarus pulex & Dijon, France & & EF467865 & EU267806 & EU267819 \\
\hline Profilicollis altmani & Enhydra lutris & $\begin{array}{l}\text { Monterey Bay, } \\
\text { California, USA }\end{array}$ & 5777 & DQ089720 & AF001838 & AY829108 \\
\hline Profilicollis botulus $^{1}$ & Somateria mollissima & Denmark & 5768 & EF467862 & EU267805 & EU267818 \\
\hline Southwellina hispida ${ }^{1}$ & ND & Baltic Sea, Finland & & EF467866 & EU267809 & EU267810 \\
\hline Southwellina hispida ${ }^{2}$ & Tigrisoma mexicanum & Veracruz, México & 5769 & EF467867 & EU267807 & EU267811 \\
\hline Centrorhynchus sp. & Falco peregrinus & California, USA & & DQ089716 & AY830155 & AY829104 \\
\hline Gorgorhynchoides bullocki & Eugerres plumieri & $\begin{array}{l}\text { Quintana Roo, } \\
\text { México }\end{array}$ & & DQ089715 & AY830154 & AY829103 \\
\hline Plagiorhynchus cylindraceus & Porcilio saber & Dijon, France & & DQ089724 & AF001839 & AY829102 \\
\hline
\end{tabular}

Six adult acanthocephalans identified as $S$. dimorpha and S. hispida were prepared for scanning electron microscopy (SEM) using standard methods (Guillén-Hernández et al., 2008). SEM facilitated observations on anterior trunk spines and hooks of the proboscis. Illustrations of $S$. dimorpha and S. hispida were prepared with the aid of a drawing tube attached to the microscope. Measurements are given in millimeters $(\mathrm{mm})$. For comparative purposes, 38 mature specimens ( 31 females and 7 males) of $S$. hispida collected from different bird species in the Gulf of Mexico and Pacific Ocean slopes were studied. In addition, vouchers of different species of polymorphids from the National Collection of Helminths (CNHE) (see García-Prieto et al., 2010), and the Harold. W. Manter Laboratory of Parasitology, Lincoln, Nebraska (HWML), were studied as follows: $S$. hispida (CNHE 6716, 6720, 6735-6736, 6689-6691, HWML 34897, 34898, 34902, 34903), S. dimorpha (HWML 34731, 34732), S. macracanthus (HWML 34527, 34528), and Hexaglandula corynosoma Travassos, 1915 (CNHE 5765, 5771-5773).

\section{Amplification and sequencing of DNA}

Two specimens of $S$. dimorpha were used for DNA extraction; 1 individual was from Los Chivos, Veracruz, México, and the other from Catemaco, Veracruz, México. These individuals were digested overnight at $56 \mathrm{C}$ in a solution containing $10 \mathrm{mM}$ Tris- $\mathrm{HCl}, \mathrm{pH} 7.6,20 \mathrm{mM} \mathrm{NaCl}$, $100 \mathrm{mM} \mathrm{Na} 2$ EDTA, pH 8.0, $1 \%$ Sarkosyl, and $0.1 \mathrm{mg} / \mathrm{ml}$ proteinase $\mathrm{K}$. After digestion, DNA was extracted from the supernatant using the DNAzol reagent (Molecular Research Center, Cincinnati, Ohio) according to the manufacturer's instructions.

Two regions of nuclear ribosomal DNA (rDNA) were amplified using the polymerase chain reaction (PCR). The near-complete SSU rDNA $(\sim 1,800 \mathrm{bp})$ was amplified in 1 fragment using the forward primer $5^{\prime}$ AGATTAAGCCATGCATGCGT and reverse primer 5'-GCAGGTTCACCTACGGAAA. The near-complete LSU rDNA ( 2,900 bp) was amplified using 2 overlapping PCR fragments of 1,400-1,500 bp. Primers for LSU amplicon 1 were forward 5'-CAAGTACCGTGAGGGAAAGTTGC and reverse $5^{\prime}$-CTTCTCCAAC(T/G)TCAGTCTTCAA; amplicon 2, forward 5'-CTAAGGAGTGTGTAACAACTCACC and reverse 5'-CTTCGCAATGATAGGAAGAGCC (García-Varela and Nadler, 2005). A partial (661-bp) sequence of mitochondrial cox 1 was amplified using the forward primer 5'-AGTTCTAATCATAA(R)GATA$\mathrm{T}(\mathrm{Y}) \mathrm{GG}$ and reverse $5^{\prime}$-TAAACTTCAGGGTGACCAAAAAATCA (Folmer et al., 1994).

PCR reactions $(25 \mu \mathrm{l})$ consisted of $10 \mu \mathrm{M}$ of each primer, $2.5 \mu \mathrm{l}$ of $10 \times$ buffer, $2 \mathrm{mM} \mathrm{MgCl}$, and $1 \mathrm{U}$ of Taq DNA polymerase (Platinum Taq, Invitrogen Corporation, São Paulo, Brazil). PCR cycling parameters for rDNA amplifications included denaturation at $94 \mathrm{C}$ for $3 \mathrm{~min}$, followed by 35 cycles of $94 \mathrm{C}$ for $1 \mathrm{~min}$, annealing at 50-58 C (optimized for each rDNA amplification) for $1 \mathrm{~min}$, and extension at $72 \mathrm{C}$ for $1 \mathrm{~min}$, followed by a post-amplification incubation at $72 \mathrm{C}$ for $7 \mathrm{~min}$. PCR cycling conditions for the cox 1 amplifications included denaturation at $94 \mathrm{C}$ for $5 \mathrm{~min}$, followed by 35 cycles of $94 \mathrm{C}$ for $1 \mathrm{~min}$, annealing at $40 \mathrm{C}$ for $1 \mathrm{~min}$, and extension at $72 \mathrm{C}$ for $1 \mathrm{~min}$, followed by a post-amplification incubation at $72 \mathrm{C}$ for $5 \mathrm{~min}$.

Each PCR product was purified using Millipore columns (Amicon, Billerica, Massachusetts). Purified products were cloned by ligation into pGEM-T vector (Promega, Madison, Wisconsin) and used to transform competent Escherichia coli (JM109). Positive clones were identified by blue/white selection, and clone (insert) size was confirmed by PCR of DNA extracts prepared from bacterial (clone) colonies. Liquid cultures for minipreps were grown in Luria broth containing $50 \mu \mathrm{g} / \mathrm{ml}$ ampicillin. Plasmids for DNA sequencing were prepared using commercial miniprep kits (QIAprep, QIAGEN, Valencia, California). Plasmids were sequenced for both DNA strands using universal (vector) and internal primers Sequencing reactions were performed using ABI Big Dye (Applied Biosystems, Boston, Massachusetts) terminator sequencing chemistry, and reaction products were separated and detected using an ABI 3730 capillary DNA sequencer. Contigs were assembled and base-calling differences resolved using Codoncode Aligner version 3.0.1 (Codoncode Corporation, Dedham, Massachusetts). The cox 1 sequences from the $2 S$. dimorpha individuals were identical; therefore, only 1 specimen was used to obtain sequences for nuclear SSU and LSU rDNA. The sequences have been deposited in the GenBank database (Table I). A database was built for 18 isolates representing 16 species of polymorphids (including 2 
isolates of $S$. hispida, 1 from México, and 1 from the Baltic Sea) with information obtained from the GenBank (Table I).

\section{Alignments}

The SSU and LSU data sets were aligned separately using ProAlign version 0.5 (Loytynoja and Milinkovitch, 2003). For each alignment, a ProAlign guide tree was constructed using corrected (for multiple hits) pairwise distances; this guide tree was used to estimate the hidden Markov model parameters $(\delta$ and $\varepsilon$ ) for progressive multiple alignment. Program (Java) memory and bandwidth were increased as required to complete the alignment. The minimum posterior probability of sites was used as the criterion for detecting and removing unreliably aligned sequence. To reduce the likelihood of excluding correctly aligned sites, the filter threshold was set to $60 \%$ minimum posterior probability. For the SSU sequences, using ProAlign to detect and remove unreliably aligned sequence by their posterior probabilities excluded 205 of 1,746 sites. For the LSU data set, 632 of 2,974 sites were excluded based on posterior probability filtering. Thus, these combined rDNA data sets included 3,883 characters after removal of unreliably aligned sites. Sequences from the mitochondrial protein coding gene cox 1 were $655 \mathrm{bp}$ in all taxa. These nucleotide sequences were readily aligned based on their inferred (in silicotranslated) cox 1 protein sequences. The concatenated 3-gene data set included 4,538 characters (filtered rDNA alignments plus cox 1 with 18 sequences).

\section{Phylogenetic analyses}

The filtered SSU and LSU rDNA alignments were combined with the cox 1 alignment to form a concatenated data set. Maximum parsimony (MP) and maximum likelihood (ML) trees were inferred using PAUP* 4.0b10 (Swofford, 2002). For ML analyses, the Akaike Information Criterion was used to assess the fit of general time reversible (GTR) nucleotide substitution models for the concatenated data set (Rodríguez et al., 1990) as implemented using Modeltest version 3.0 (Posada and Crandall, 1998). The best-fit substitution model for the concatenated data set it was GTR + I + G. For phylogenetic analysis, this GTR model with invariable sites $(+\mathrm{I})$ and rate heterogeneity $(+\mathrm{G})$ (Yang, 1994) was used. Tree searches were performed using $100(\mathrm{ML})$ and 1,000 (MP) random taxon addition heuristic searches with branch and bound searches, respectively. Clade support was assessed by bootstrap resampling with 1,000 (ML) or 10,000 (MP) bootstrap replicates. MrBayes version 3.0b4 (Huelsenbeck and Ronquist, 2001) was used to analyze the concatenated data set, sampling every 5,000 trees over 5,000,000 generations (burnin determined empirically). For this analysis, a character partition corresponding to the 3 loci (nuclear SSU, LSU, and mitochondrial cox 1) was invoked. To each partition the best substitution model was GTR + I + G (Table II). The priors for the proportion of invariable sites (pinvarpr) were fixed separately for each partition with the values estimated by Modeltest (pinvarpr $=0.4044$ for SSU, pinvarpr $=0.3893$ for LSU, and pinvarpr $=$ 0.3411 for cox 1$)$.

To compare trees representing specific alternative phylogenetic hypotheses, topological constraints were defined on trees obtained from MP and ML analyses of the concatenated (SSU + LSU + cox 1) data set. Differences between unconstrained (best) and constrained trees representing alternative hypotheses were evaluated using the Shimodaira and Hasegawa likelihood test (Shimodaira and Hasegawa, 1999) and Templeton's (1983) modified parsimony test as executed in PAUP*. Trees were drawn using RETREE and DRAWGRAM from PHYLIP (Felsenstein, 1999). The observed (uncorrected) genetic differentiation between taxa was represented using the p-distance on the filtered concatenated dataset. The filtered concatenated alignment has been deposited in TreeBASE (Sanderson et al., 1994).

\section{RESULTS}

The concatenated data set of 3 genes $(\mathrm{SSU}+\mathrm{LSU}+\operatorname{cox} 1)$ included 18 taxa, with 4,538 characters, of which 900 were parsimony informative. The branch and bound search resulted in a single tree, with a consistency index (C.I.) $=0.594$ and a length of 3,534 steps (Fig. 1). The tree indicates that Polymorphidae is a monophyletic group composed of 5 main clades. However,

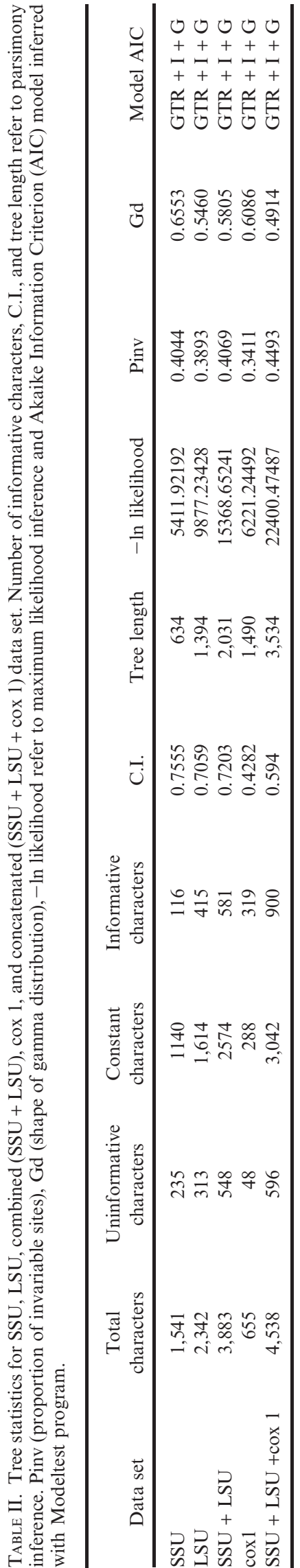




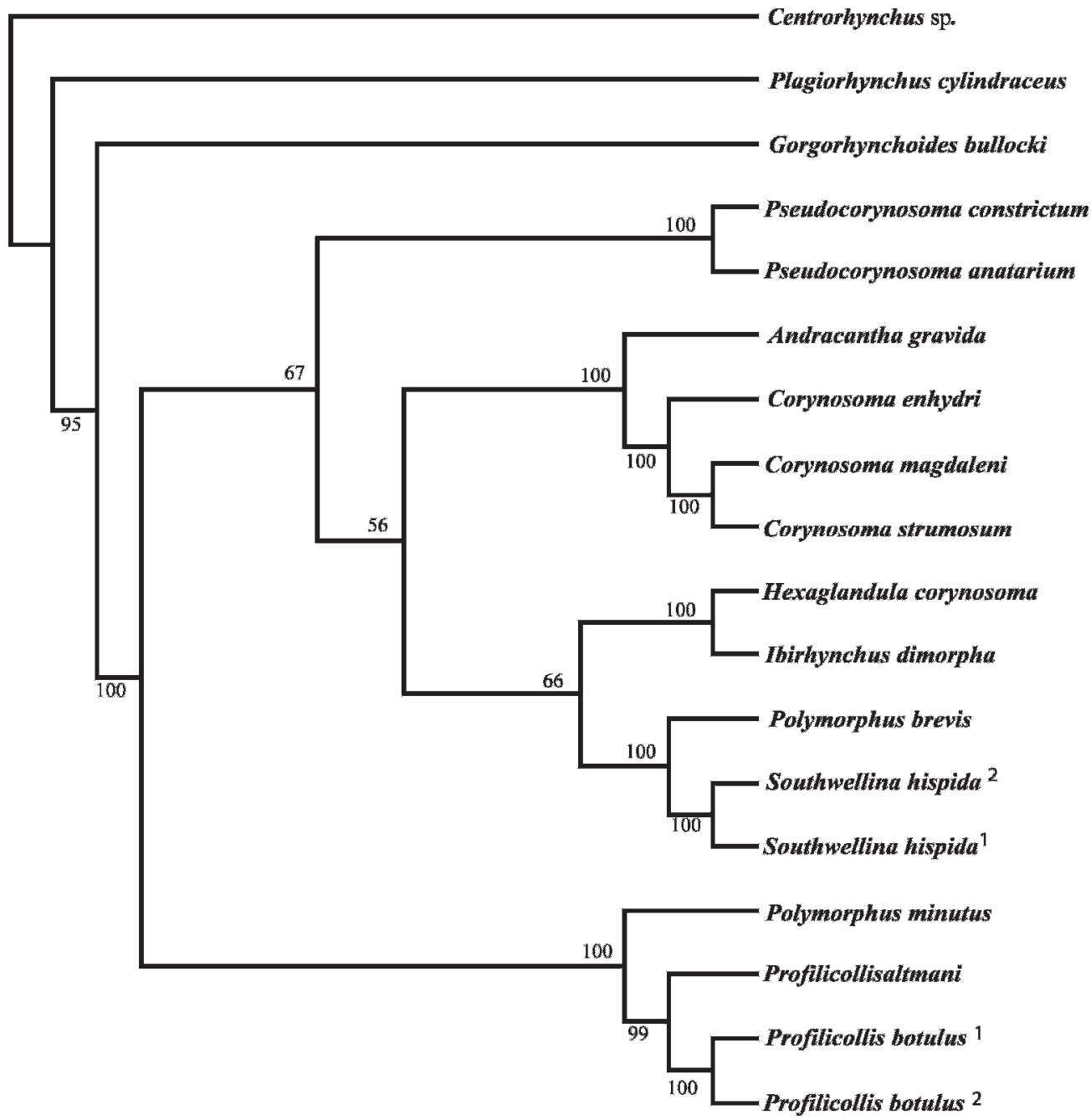

FIGURE 1. MP tree (3,534 steps) inferred from the concatenated SSU + LSU + cox 1 data set. Numbers above internal nodes show MP bootstrap clade frequencies.

Polymorphus and Southwellina are both paraphyletic. Southwellina dimorpha were included as sister taxa to H. corynosoma; this clade had $100 \%$ bootstrap support. The 2 isolates of $S$. hispida appear as sister taxa to Polymorphus brevis Van Cleave, 1916 and also had $100 \%$ bootstrap support (Fig. 1). The ML analysis yielded a single tree with $-\ln =22400.4748$. The ML topology also yielded same main 5 clades as in the MP tree, but relationships among the clades were sometimes different for the position of Pseudocorynosoma (Fig. 2). The position of $S$. dimorpha with respect to $H$. corynosoma and the position of $S$. hispida with respect to $P$. brevis were also consistent between MP and ML analyses and are supported by high bootstrap values. To examine the separate contribution of each data set to the systematic position of the 2 species of Southwellina, additional phylogenetic analyses were conducted using SSU, LSU, and cox 1 alone and with the combined (SSU + LSU) data set (Table II). In addition, a Bayesian analysis was inferred with the concatenated $(\mathrm{SSU}+\mathrm{LSU}+\operatorname{cox} 1)$ data set. Three partitions were performed, and each partition corresponded with each gene. The Bayesian tree also supported the paraphyly of Southwellina. All ML and MP trees derived from individual and combined analyses as well as the Bayesian inference supported the paraphyly of Southwellina and the sister relationship of $H$. corynosoma with $S$. dimorpha (trees not shown).

\section{DESCRIPTION}

\section{Ibirhynchus gen. nov.}

Diagnosis (based on 3 gravid females and 6 males): Trunk cylindrical, swollen in anterior region and slender posteriorly. Proboscis short, barrelshaped, with 17 to 24 longitudinal rows of 9 to 14 hooks each. Sexual dimorphism in body size with females larger than males. Females possessing single field of spines in anterior region of trunk and males with 2 fields of spines. Neck long, proboscis receptacle double-walled. Lemnisci flat, broad, about same length, shorter than proboscis receptacle, cylindrical in shape. Male with 2 testes in tandem, located in anterior part of trunk, with 4 tubular cement glands (Figs. 3A-F; 4A, B).

\section{Taxonomic summary}

Type species: Ibirhynchus dimorpha (Schmidt, 1973) n. comb.

Host: White ibis, Eudocimus albus (L.), and whooping crane, Grus americana (L.) (definitive hosts); crayfish, Procambarus clarkii (Girard); and crawfish, Cambarellus shufeldtii (Faxon) (intermediate hosts).

Geographic distribution: Gulf of Mexico. 


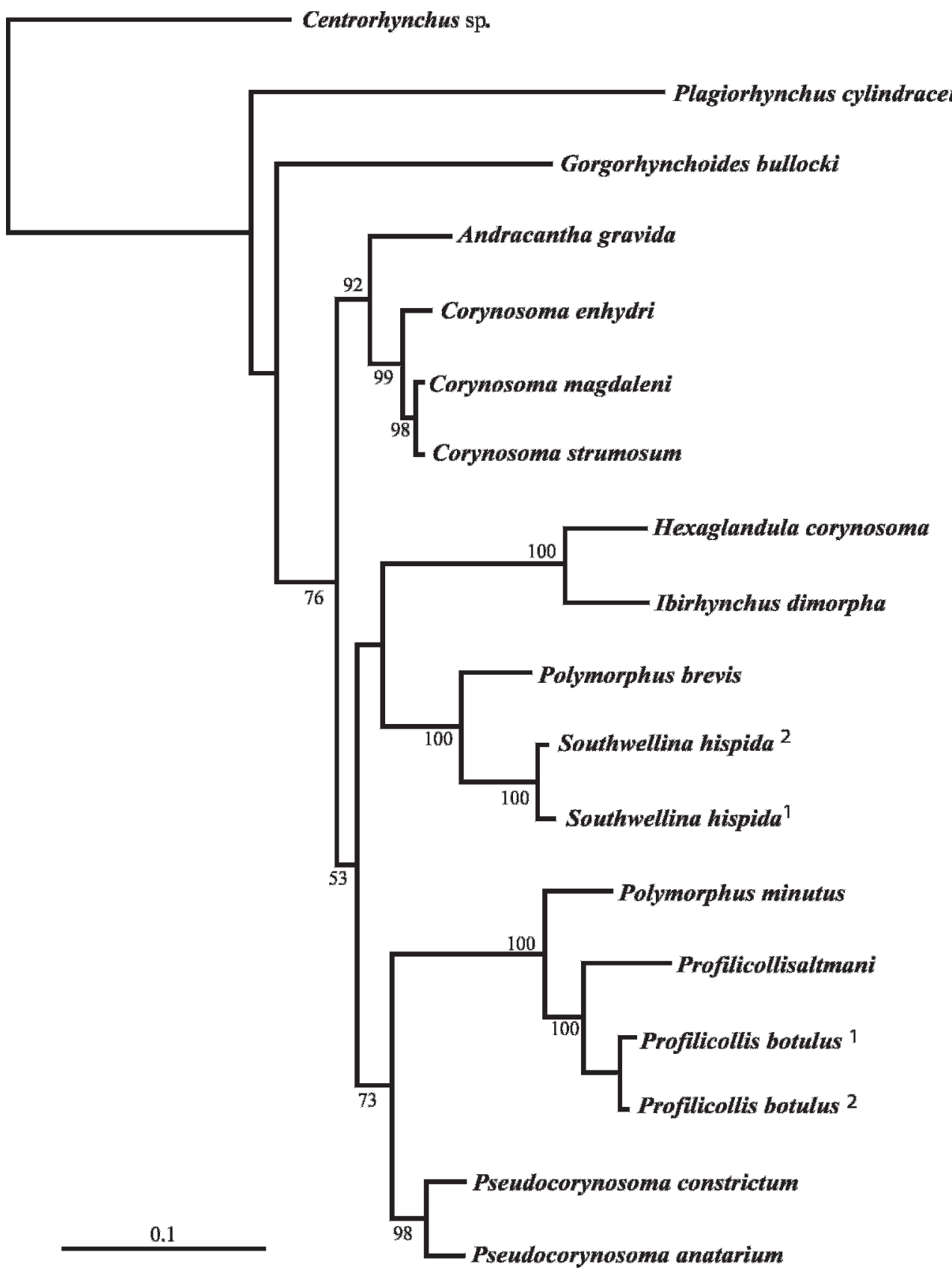

FIGURE 2. ML tree ( - ln likelihood 22400.4748) inferred from the concatenated SSU + LSU + cox 1 data set. Numbers above internal nodes show ML bootstrap clade frequencies.

\section{Remarks}

The erection of the new genus to accommodate $S$. dimorpha is based on different data sources, i.e., the use of 3 molecular markers ( 2 nuclear and 1 mitochondrial) from which the phylogenetic position of the new genus, as well as levels of genetic divergence, were obtained. In addition, a detailed morphological comparison was made using both light and electron microscopy; some ecological information (host preference) also was considered. The new genus (Ibirhynchus gen. nov.) possesses a set of morphological characters that sets it apart from all the other congeners within Polymorphidae, i.e., the presence of a single field of spines in the anterior region of the trunk in females, 2 fields of spines in the region anterior of trunk in males, the presence of 4 tubular cement glands in males, and a barrel-shaped proboscis. In addition, sexual dimorphism in terms of spine distribution in the anterior region of the trunk is found only in the new genus (and in its only species, I. dimorpha); this trait represents an autapomorphy for the genus.

Our specimens, 6 males and 3 females collected from the type host white ibis from Veracruz state, México, were determined as $S$. dimorpha based on morphological criteria, following the description of this species provided by Schmidt (1973). To corroborate our identification, specimens of $S$. dimorpha were requested from HWML (vouchers 34731, 34732) and studied. Southwellina dimorpha is diagnosed by having a cylindrical trunk, swollen in the anterior region and slender in the posterior region, and a short and barrel-shaped proboscis possessing 17 to 24 longitudinal rows of 

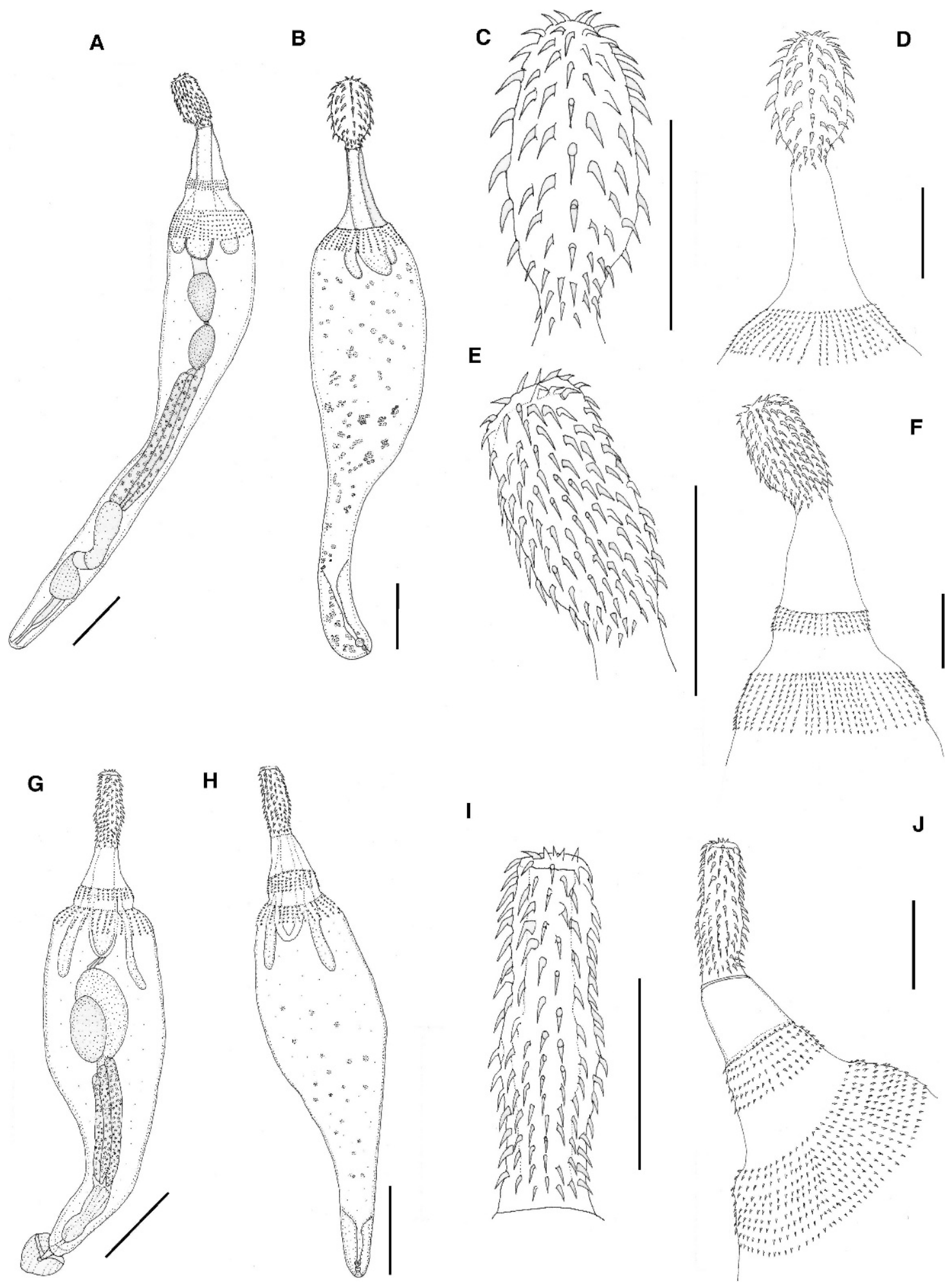

I

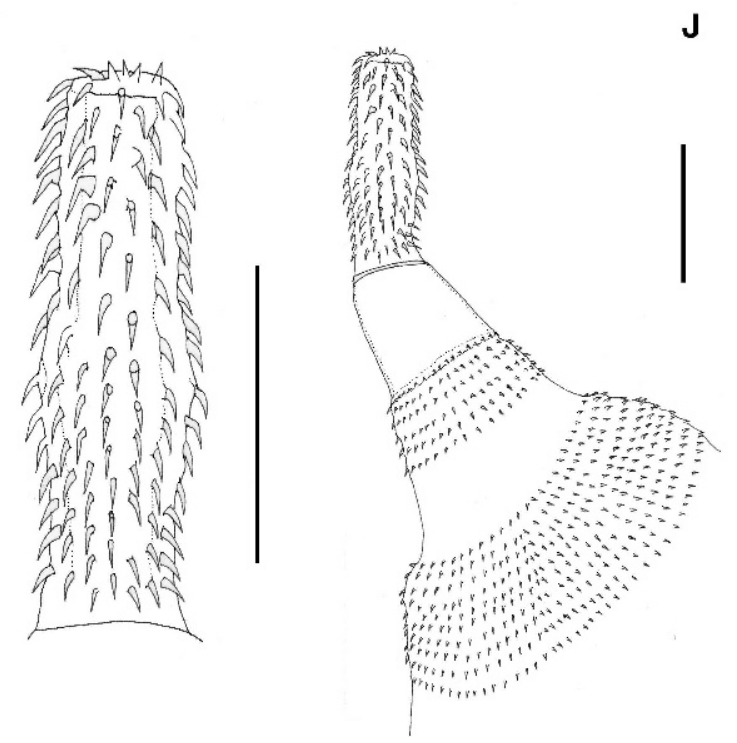

Figure 3. Line drawings of Ibirhynchus dimorpha n. gen., n. comb. from Eudocimus albus, Los Chivos, Veracruz state, México. (A) Adult male. (B) Adult female. (C) Proboscis female. (D) Anterior region of the trunk of female. (E) Proboscis of male. (F) Anterior region of trunk of male. Line drawings of Southwellina hispida from Tigrisoma mexicanum, Tlacotalpan, Veracruz, México. (G) Adult male. (H) Adult female. (I) Proboscis of male. (J) Anterior region of trunk of male. Bars $=1 \mathrm{~mm}(\mathrm{~A}-\mathrm{J})$. 

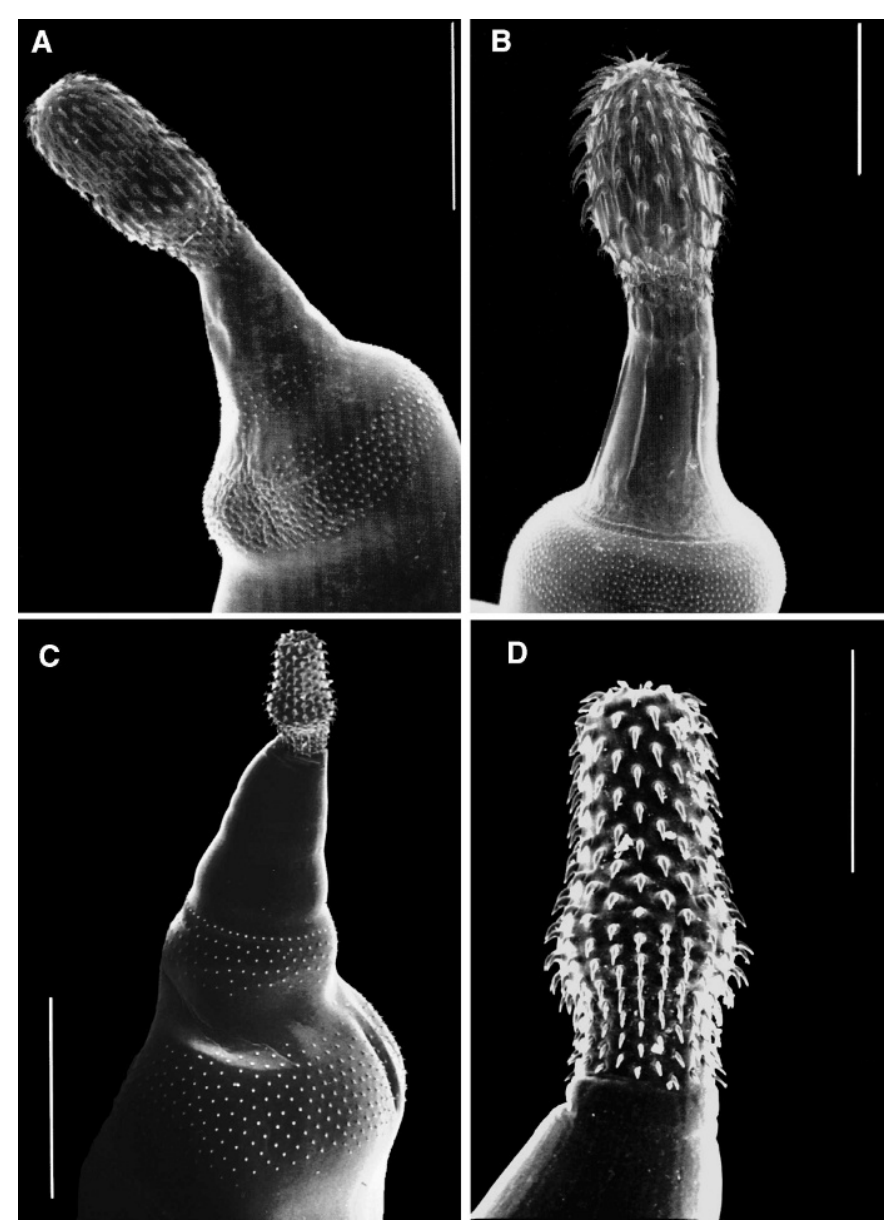

FIGURE 4. Scanning electron micrographs of proboscis and trunk of adults of Ibirhynchus dimorpha n. gen., n. comb. (A) Male. (B) Female. Scanning electron micrographs of proboscis and trunk of adults of Southwellina hispida. (C) Male. (D) Female. Bars $=1 \mathrm{~mm}(\mathrm{~A}-\mathrm{C})$ and $400 \mu \mathrm{m}$ (D).

hooks with 9 to 14 hooks each. Females possess a single field of spines in the anterior region of the trunk and males have 2 fields of spines. Males possess 2 testes located in tandem in the anterior part of the trunk, with 4 tubular cement glands.

The molecular phylogenetic analyses showed that Southwellina is a paraphyletic genus and that $S$. dimorpha is closely related to $H$. corynosoma. Here, we propose the erection of a new genus to accommodate $S$. dimorpha and argue that it cannot be considered as a species of Hexaglandula because it possesses several morphological and ecological traits that guarantee its validity. A morphological synapomorphy for Hexaglandula is the presence of 6 cement glands in males, whereas the new genus possesses 4 cement glands. In addition, the new genus exhibits sexual dimorphism in the number of field of spines in the anterior portion of trunk (which represents an autapomorphy for the new genus). Furthermore, the new genus seems to be specific for the white ibis, whereas all the species of Hexaglandula are only found in typically fish-eating birds (herons). These characters (number of cement glands, fields of spines in the anterior portion of trunk, and host preference) are very important in the taxonomy of polymorphids and represent key characters for the distinction and classification of the entire family (Schmidt, 1973).

Currently, Ibirhynchus gen. nov. is monotypic, including the species $S$. dimorpha that was transferred to this genus as a new combination. As a result of this taxonomic change, the generic diagnosis of Southwellina had to be slightly emended to include solely species with 2 fields of spines in the anterior region of the trunk in both sexes, and with a modification in the number of longitudinal rows of spines in the proboscis and the number of hooks in each row.

\section{REDESCRIPTION}

\section{Southwellina Witenberg, 1932}

Diagnosis: Trunk cylindrical, swollen in anterior region and slender in posterior region. Both sexes contain 2 fields of spines in anterior region of trunk. Proboscis subcylindrical, slightly swollen in middle region and slender in anterior and posterior region, covered with 16 to 20 longitudinal rows of 12 to 17 hooks each, proboscis receptacle double-walled. Lemnisci longer than proboscis receptacle, cylindrical in shape. Females larger than males. Male possessing 2 oval-shaped testes contiguous or slightly tilted located in anterior portion of trunk, with 4 tubular cement glands (Figs. 3G-J; 4C, D).

\section{Taxonomic summary}

Type species: Southwellina hispida Van Cleave 1925.

Other species: Southwellina macracanthus.

Host: Fish-eating birds (herons, cormorants, grebes, pelicans and eagles) (definitive hosts); amphibians, reptiles, teleosts (paratenic); crayfish (intermediate hosts).

Geographic distribution: Cosmopolitan.

\section{Remarks}

The 38 mature adults of $S$. hispida collected in México were used for the morphological study and a comparison with specimens of $S$. hipida used by Schmidt (1973) in his revision of Southwellina. Voucher specimens of S. hispida (HWML) (accessions 34898, 34897, 34902, 34903) were used for comparison with our specimens. Based on the examination of these specimens, we concluded and confirmed that our specimens belong to $S$. hispida by possessing 2 fields of spines in the anterior region of the trunk in both sexes and males possessing 4 tubular cement glands. With respect to $S$. macracanthus, we also examined specimens from the HWML (vouchers 34527 and 34528) and confirmed that this species possesses the diagnostic characters of Southwellina, even though the species description is based solely on cystacanths.

\section{DISCUSSION}

The MP, ML, and Bayesian analyses inferred from the concatenated dataset of 3 genes showed that Polymorphidae is a monophyletic group; this result is strongly supported by bootstrap resampling, Bayesian posterior probabilities (BPP), and corroborated by findings of previous phylogenetic studies (see García-Varela and Pérez Ponce de León, 2008; García-Varela et al., 2009). The MP and ML trees also confirmed that Polymorphus (P. brevis and P. minutus) and Southwellina ( $S$. hispida and $S$. dimorpha) are paraphyletic, suggesting that both genera represent species that should be re-examined and reclassified using morphological, ecological, and molecular data. In the present study, we included 2 of the 3 species of Southwellina.

Southwellina hispida was originally described as Arhythmorhynchus hispida based on cystacanths found in a frog from Japan (Van Cleave, 1925). Later, adults of A. hispida were described from a heron (Nycticorax nycticorax) (Fukui, 1929). Witenberg (1932) revised the diagnosis of $A$. hispida and elevated it to generic rank with the name Southwellina, but Yamaguti (1963) synonymized it with Arhythmorhynchus, which was accepted by other authorities (Van Cleave, 1945; Golvan, 1956). The diagnostic morphologic differences between Southwellina and Arhythmorhynchus include the presence of 1 or 2 fields of spines in the anterior region of the trunk in at least 1 sex, trunk length, proboscis shape, and number of cement glands in males. Based on these morphological features, Schmidt (1973) recognized the validity of the genus Southwellina and proposed that it was composed of 3 species ( $S$. hispida, S. dimorpha, and $S$. macracanthus). 
TABLE III. Comparative features among Southwellina, Hexaglandula, and Ibirhynchus gen. nov.

\begin{tabular}{|c|c|c|c|}
\hline Trunk & Long and slender & Short and compact & Long and slender \\
\hline Spines in the trunk & $\begin{array}{l}2 \text { fields of spines on the anterior } \\
\text { region on both sexes }\end{array}$ & $\begin{array}{l}\text { Single field of spines on the } \\
\text { anterior region on both sexes }\end{array}$ & $\begin{array}{l}\text { Single field of spines on the anterior } \\
\text { region in females and } 2 \text { fields of spines } \\
\text { on males }\end{array}$ \\
\hline Proboscis & $\begin{array}{l}\text { Subcylindrical, slightly swollen in } \\
\text { the middle region and slender on the } \\
\text { anterior and posterior region }\end{array}$ & $\begin{array}{l}\text { Subcylindrical, slightly swollen in } \\
\text { the middle region and slender on } \\
\text { the anterior and posterior region }\end{array}$ & Short, barrel-shaped \\
\hline Cement glands & 4 tubular & 6 tubular & 4 tubular \\
\hline Adult host & $\begin{array}{l}\text { Herons, cormorants, grebes, pelicans, } \\
\text { and eagles }\end{array}$ & $\begin{array}{l}\text { Yellow crowned night heron } \\
(\text { Nyctanassa violacea })\end{array}$ & White ibis (Eudocimus albus) \\
\hline
\end{tabular}

In the present study, we used sequences of 2 isolates of the type species ( $S$. hispida) collected from a wide geographic range (México and Denmark) and specimens of $S$. dimorpha collected from the type host (white ibis) from Veracruz state, México. The tree topologies derived from MP and ML analyses with a concatenated dataset of 3 genes placed the 2 isolates of $S$. hispida and $S$. dimorpha in 2 separate clades with strong bootstrap support. This result conflicts with their placement as congeners within Southwellina that is based on morphologic grounds. However, to test the paraphyly of Southwellina, the alternative hypothesis ( $S$. hispida and $S$ dimorpha as a monophyletic group) was evaluated with MP and ML analyses using the concatenated data set of 3 genes. The constrained analyses of maximum parsimony and maximum likelihood showed a tree with a length of 3,756 steps and $-\ln =22823.5321$, respectively, whereas original hypotheses of MP and ML yielded a tree with a length of 3,534 steps and $-\ln =22400.4748$, respectively. Based on both Templeton's (1983) parsimony test and the Shimodaira and Hasegawa (1999) likelihood test, the alternative hypotheses of $S$. hispida and $S$ dimorpha as monophyletic is significantly worse than the best trees represented in Figures 1 and 2. The genetic divergence between the 2 isolates of $S$. hispida and $S$. dimorpha ranged from 10.7 to $11 \%$; this divergence value is even higher compared with values obtained between congeneric species for other polymorphids in this phylogenetic analysis, i.e., Corynosoma (0.7-1.9\%), Profilicollis (4.5-4.7\%), and Pseudocorynosoma $(2.0 \%)$. The phylogenetic position of S. hispida and S. dimorpha within Polymorphidae, their high level of genetic divergence, and morphologic differences (proboscis shape, and the presence of 1 or 2 fields of spines on the anterior region of the trunk in females; see Table III) support recognition of these separate evolutionary lineages as independent genera. Southwellina hispida, the type species, is retained in Southwellina with S. macracanthus. Both species are restricted to fish-eating birds (eagles, cormorants, grebes, pelicans, and herons). A new genus, Ibirhynchus gen. nov., is designated for $S$. dimorpha (see Remarks above).

Our phylogenetic hypotheses, based on the concatenated dataset of 3 genes plus the morphologic and ecological evidence, revealed the presence of a new genus, Ibirhynchus, within Polymorphidae. Our analyses also confirm that Polymorphus is paraphyletic, suggesting that the genus represents a complex of species that should be reexamined and reclassified using morphological, ecological, and molecular data. Therefore, the inclusion of more congeneric species of Polymorphus and of other genera such as Bolbosoma, Arythmorhynchus, and Diplospinifer will be needed to produce a robust classification scheme, with the aim of better understanding of the evolutionary history of this enigmatic group of acanthocephalans.

\section{ACKNOWLEDGMENTS}

We are grateful to Berenit Mendoza-Garfias for help with the scanning electron microscopy, and Patricia de la Torre and Laura Marquez for help with the use of the DNA sequencer. This research was supported by the Programa de Apoyo a Proyectos de Investigación e Inovación Tecnológica (PAPIIT 215709) and the Consejo Nacional de Ciencia y Tecnología (CONACYT 102062) to MG-V and by the project CGL2007-63221 of the Ministry of Education and Science (MEC) of Spain to FJA and MG-V.

\section{LITERATURE CITED}

American Ornithologists' Union. 1998. Check-list of North American birds, 7th ed. Washington, D.C., 829 p.

Amin, O. M. 1985. Classification. In Biology of the Acanthocephala, B. B. Nickol, and D. W. T Crompton (eds.). Cambridge University Press, Cambridge, U.K., p. 27-72.

Aznar, F. J., G. Pérez Ponce de León, and J. A. Raga. 2006. Status of Corynosoma (Acanthocephala: Polymorphidae) based on anatomical, ecological and phylogenetic evidence, with the erection of Pseudocorynosoma $\mathrm{n}$. gen. Journal of Parasitology 92: 548-564.

Courtney, C. H., and D. J. Forrester. 1974. Helminth parasites of the brown pelican in Florida and Louisiana. Journal of the Helminthological Society of Washington 41: 89-93.

Dezfuli, B. S., S. Volponi, I. Beltrami, and R. Poulin. 2002. Intra- and interspecific density-dependent effects on growth in helminth parasites of the cormorant, Phalacrocorax carbosinensis. Parasitology 124: $537-544$

Dimitrova, Z. M., And B. B. Georgiev. 1994. Ardeirhynchus n. gen. (Palaeacanthocephala: Polymorphida: Polymorphidae), with a redescription of A. spiralis (Rudolphi, 1809) n. comb. Systematic Parasitology 29: 149-158.

Felsenstein, J. 1999. PHYLIP (phylogeny inference package), version 3.572. University of Washington, Seattle, Washington.

Folmer, O., M. Black, W. Hoeh, R. Lutz, and R. Vrijenhoek. 1994. DNA primers for the amplification of mitochondrial cytochrome $c$ oxidase subunit I from diverse metazoan invertebrates. Molecular Marine Biology and Biotechnology 3: 294-299.

Font, W. F. 2007. Parasites of Hawaiian stream fishes: Sources and impacts. Bishop Museum Bulletin in Cultural and Environmental Studies 3: $157-169$

FukUI, T. 1929. On some acanthocephala found in Japan. Annotto Zoology Japan 12: 255-270.

García-Prieto, L., M. García-Varela, B. Mendoza-Garfias, and G. Pérez-Ponce de León. 2010. Checklist of the Acanthocephala in wildlife vertebrates of México. Zootaxa 2419: 1-50. 
García-Varela, M., and S. A. Nadler. 2005. Phylogenetic relationships of palaeacanthocephala (Acanthocephala) inferred from SSU and LSU rDNA gene sequences. Journal of Parasitology 91: 1401-1409.

- And G. Pérez-Ponce de León. 2008 Validating the systematic position of Profilicollis Meyer, 1931 and Hexaglandula Petrochenko, 1950 (Acanthocephala: Polymorphidae) using cytochrome c oxidase (cox 1). Journal of Parasitology 94: 212-217.

$\longrightarrow,-$ F. J. Aznar, And S. A. NAdLer. 2009. Systematic position of Pseudocorynosoma and Andracantha (Acanthocephala, Polymorphidae) based on nuclear and mitochondrial gene sequences. Journal of Parasitology 95: 178-185.

Golvan, Y. J. 1956. Acanthocéphales d'oiseaux. Première note. Description d'Arhythmorhynchus longicollis (Villot 1875) et revision du genre Arhythmorhynchus Lühe 1911 (Acanthocephala). Annales de Parasitologie Humaine et Comparée 31: 199-224.

Guillén-Hernández, S., M. García-Varela, and G. Pérez-Ponce de LeÓn. 2008. First record of Hexaglandula corynosoma (Travassos, 1915) Petrochenko, 1958 (Acanthocephala: Polymorphidae) in intermediate and definitive hosts in México. Zootaxa 1873: 61-68.

HoberG, E. P. 1986. Aspects of ecology and biogeography of Acanthocephala in Antarctic seabirds. Annales de Parasitologie Humaine et Comparée 61: 199-214.

Howell, S. N. G., And S. Webb. 1995. A guide to the birds of México and Northern Central America. Oxford University Press, New York, New York, $851 \mathrm{p}$.

Huelsenbeck, J. P., And F. Ronquist. 2001. MrBayes: Bayesian inference of phylogeny. Version 3.0b4. Distributed by the author. Department of Biology, University of Rochester, Rochester, New York.

Loytynoja, A., And M. C. Milinkovitch. 2003. A hidden Markov model for progressive multiple alignment. Bioinformatics 19: 1505-1513.

Nickol, B. B., D. W. T. Crompton., and D. W. Searle. 1999. Reintroduction of Profilicollis Meyer, 1931, as a genus in Acanthocephala: Significance of the intermediate host. Journal of Parasitology 85: 716-718.

- R. W. Heard, and N. F. Smith. 2002. Acanthocephalans from crabs in the southeastern US, with the first intermediate hosts known for Arhythmorhynchus frassoni and Hexaglandula corynosoma. Journal of Parasitology 88: 79-83.

Norman, O. D., C. K. Blend, And C. K. Anderson. 2003. Endohelminths from the brown pelican, Pelecanus occidentalis, and the American white pelican, Pelecanus erythrorhynchus, from Galveston Bay, Texas, U.S.A., and checklist of pelican parasites. Comparative Parasitology 70: $140-154$.

Petrochenko, V. I. 1958. Acanthocephala of domestic and wild animals, vol. II. Izdatel'stvo Akademii Nauk SSSR, Vsesoyuznoe Obshchestvo Gel'mintologov, Moscow, Russia, 478 p.
Posada, D., and K. A. Crandall. 1998. Modeltest: Testing the model of DNA substitution. Bioinformatics 9: 817-818.

Richardson, J. D., And R. A. Cole. 1997. Acanthocephala of the bald eagle (Haliaeetus leucocephalus) in North America. Journal of Parasitology 83: 540-541.

- AND W. F. Font. 2006. The Cajun dwarf crawfish (Cambellus shufeldtii): An intermediate host for Southwellina dimorpha (Acanthocephala). Journal of the Arkansas Academy of Science 60: 192193.

Rodríguez, F., J. F. Oliver, A. Marin, and J. R. Medina. 1990. The general stochastic model of nucleotide substitution. Journal of Theoretical Biology 142: 817-818.

Sanderson, M. J., M. J. Donoghue, W. Piel, and T. Eriksson. 1994. TreeBASE: A prototype database of phylogeny analyses and an interactive tool for browsing the phylogeny of life. America Journal of Botany 81: 183.

Schmidt, G. D. 1973. Resurrection of Southwellina Witenberg, 1932, with a description of Southwellina dimorpha sp. n., a key to genera in Polymorphida (Acanthocephala). Journal of Parasitology 59: 299305.

. 1985. Development and life cycles. In Biology of Acanthocephala, B. B. Nickol and D. W. T. Crompton (eds.). Cambridge University Press, Cambridge, U.K., p. 273-286.

Shimodaira, H., and M. Hasagawa. 1999. Multiple comparisons of loglikelihoods with applications to phylogenetic inference. Molecular Biology and Evolution 16: 1114-1116.

SwOFFord, D. L. 2002. PAUP 4.0b10. Phylogenetic analysis using parsimony (and other methods). Sinauer Associates, Sunderland, Massachusetts.

Templeton, A. R. 1983. Phylogenetic inference from restriction endonuclease cleavage site maps with particular reference to the humans and apes. Evolution 37: 221-224.

Van Cleave, H. J. 1925. Acanthocephala from Japan. Parasitology 17: 149-156.

- 1945. The status of the acanthocephalan genus Arhythmorhynchus, with particular references to the validity of $A$. brevis. Transactions of American Microscopical Society 64: 133-137.

Ward, H. L., AND H. A. WINTER. 1952. Juvenile Acanthocephala from the yellowfin croaker, Umbrina roncador, with description of a new species of the genus Arhythmorhynchus. Transactions of American Microscopical Society 71: $154-156$

WitenBerG, G. 1932. Akanthocephalen-studien II. Ueberg das system der Akanthocephalen. Bolletin Zoology Napoli 3: 253-266.

Yamaguti, S. 1963. Systema helminthum, vol. V. Acanthocephala. Interscience Publishers, New York, 423 p.

YANG, Z. 1994. Estimating the patterns of nucleotide substitution. Journal of Molecular Evolution 39: 105-111. 